\title{
Corrosion Behavior of Chemically Deposited Single and Bi-layered Conducting Polymer Coatings on Mild Steel
}

\author{
M. Mobin* and Nelofar Tanveer \\ Department of Applied Chemistry, Faculty of Engineering \& Technology, Aligarh Muslim \\ University, Aligarh 202002, India
}

Received 18 November 2009; accepted 3 April 2011

\begin{abstract}
The emeraldine base (EB) was synthesized by chemically oxidative polymerization using ammonium persulphate as an oxidant in hydrochloride aqueous medium. The polymer was chemically deposited on mild steel specimens using tetra methyl urea (TMU) as solvent through solvent evaporation method. The coating of polypyrrole (PPy) on carbon steel was deposited by chemical polymerization. A bi-layered polymer coating comprising of inner coat of PPy with top coat of EB (PPy/EB) was also deposited on mild steel following identical procedure. The deposited EB, PPy and $\mathrm{PPy} / \mathrm{EB}$ coatings were characterized by Fourier Transform Infrared (FTIR) Spectroscopy and Scanning Electron Microscopy (SEM). The anticorrosive properties of single and bi-layered coatings was investigated in major corrosive environments such as $0.1 \mathrm{M} \mathrm{HCl}, 5 \% \mathrm{NaCl}$ solution, artificial seawater, distilled water, tap water and open atmosphere by conducting various corrosion tests which include: immersion test, open circuit potential measurements, potentiodynamic polarization measurements, and atmospheric exposure test.

The results of immersion tests showed that the $\mathrm{PPy} / \mathrm{EB}$ coating gave best protection in all media under investigation, the protection efficiency being in the range of 72 to $79 \%$ after 30 days of immersion. The result of OCP measurements showed significant positive shift in the corrosion potential for single as well as bi-layered coatings in all corrosive medium under investigation; the bi-layered coating showing more positive corrosion potential. The potentiodynamic polarization studies also confirmed lower corrosion rates for $\mathrm{PPy} / \mathrm{EB}$ coating than the single polymer coatings.
\end{abstract}

Keywords: emeraldine base coating, polypyrrole coating, polypyrrole/emeraldine base coating, immersion test, open circuit potential, potentiodynamic polarization.

\footnotetext{
*Corresponding author. E-mail address: drmmobin@hotmail.com
} 


\section{Introduction}

A number of methods for the protection of metals against corrosion are known, but looking for new method of corrosion control continues to be subject of intensive research. Since their discovery in late 1970 by Heeger, MacDiarmid and Shirakawa [1-3] intrinsically conducting polymers, because of their unique combination of physical and chemical properties and possibility of both chemical and electrochemical synthesis, have drawn the attention of scientists and engineers for various application possibilities. The conducting polymers, which possess the electronic properties of semiconductors and processing advantages of conventional polymers, have widely been studied for corrosion protection during the last few years.

Since the first reported work on the corrosion protection of metals using conducting polymers in 1981 [4], a large number of studies with focus mainly on polyaniline [5-10] and polypyrrole [11-15] have been carried out. Nevertheless, the polyaniline is more challengeable due to low cost of aniline monomers as compared to pyrrole, its environmental stability and the easy solution processing. The conducting polymers are generally electrochemically synthesized on the mild steel and are used for protection against corrosion. However, the film forming electropolymerization of all conducting polymers at oxidizable metals has been hindered by several thermodynamic as well as kinetic problems. The metals oxidation thermodynamic potentials are significantly lower than those of conducting monomers. As a consequence, the metallic electrode subjected to electropolymerization generally undergoes strong anodic dissolution before the oxidation potential of the monomer can be reached, thus preventing the occurrence of electropolymerization reaction. A successful electropolymerization of conducting polymers on oxidizable metals demands the establishment of convenient medium parameters (e.g., solvents, supporting electrolyte, $\mathrm{pH}$ ), which will strongly passivate the metal without impeding the electropolymerization process.

The chemically deposited emeraldine base on iron and steels was found to protect stainless steel against corrosion in acid chloride environment [16]. Later, Santos et al. [17] showed that similar chemical films were also able to protect carbon steel in $3 \% \mathrm{NaCl}$ solution. In comparison between the conducting emeraldine salt and non-conducting emeraldine base forms of polyaniline, the majority of the studies show that in $\mathrm{NaCl}$ solution it is the non-conducting form that provides the best protection $[18,19]$, whereas in $\mathrm{HCl}$ it appears that it is the conducting form which provides the better protection [20] with the undoped nonconducting form having poor adhesion [21].

Despite the success claimed for conducting polymer coatings as corrosion protection coatings a number of problems associated with these coatings prohibit them as replacement for traditional coating systems. One of the major drawback, that limits the availability of conducting polymer is the limited number of conjugated $\pi$-bond coatings monomer that are essential for electrical conductivity. One possible way to overcome this is to synthesize one polymer at the top of another polymer. Tan and Blackwood [22] studied multilayered coatings, consisting of combination of the conducting polymers polyaniline and 
polypyrrole, which were galvanostatically deposited on both carbon steel and stainless steel. Potentiodynamic polarization was used to assess the ability of these polymers to provide an effective barrier to corrosion in chloride environments. The performance of their multilayered coating on carbon steel was not sufficiently better than that of single polyaniline coating. However, in case of stainless steel the multilayered coating proved to be significantly better than the single polyaniline coating, especially at protecting against pitting corrosion. It was found that the degree of protection was a function of deposition order of the copolymer, with films consisting of a polyaniline layer on the top of a polypyrrole layer yielding the best results.

The present work was undertaken to investigate the corrosion behaviour of chemically deposited EB, PPy and PPy/EB coatings on carbon steel in different corrosive environments. The tests carried out during investigations include: immersion test, free corrosion potential measurements, potentiodynamic polymerization measurements and atmospheric exposure test.

\section{Experimental}

\section{Preparation of specimen}

Carbon steel sheets of chemical composition (in weight \%) C: 0.296; Cr: 0.078; Ni: 0.087; $\mathrm{Cu}$ : 0.052; $\mathrm{Si}: 0.003$ and Fe balance) were obtained commercially. Specimens of dimension $40 \times 15 \times 1.3 \mathrm{~mm}$ were cut from the steel sheet and were abraded sequentially with 180, 400, and 600 grit $\mathrm{SiC}$ papers. The abraded specimens were degreased with acetone and finally washed with water and dried. Before any experiment, the specimens were subjected to above treatment and freshly used with no further storage.

\section{Synthesis and preparation of emeraldine base coating}

Emeraldine base was synthesized by chemically oxidative polymerization using ammonium persulphate $\left[\left(\mathrm{NH}_{4}\right)_{2} \mathrm{~S}_{2} \mathrm{O}_{8}\right]$ as an oxidant in hydrochloride aqueous medium. $10 \mathrm{~mL}(0.1097$ mole $)$ of aniline were dissolved in $150 \mathrm{~mL}$ of $1.5 \mathrm{M} \mathrm{HCl}$ aqueous solution in a $500 \mathrm{~mL}$ glass bulb and cooled to $0{ }^{\circ} \mathrm{C}$. The oxidizing agent was prepared by dissolving $12.5 \mathrm{~g}$ (0.0548 mole) of ammonium persulfate in 150 $\mathrm{mL}$ of $1.5 \mathrm{M} \mathrm{HCl}$ aqueous solution. Aniline solution was vigorously stirred and the oxidant solution was added drop wise. The addition was performed at $0{ }^{\circ} \mathrm{C}$ during a period of 1 hour. After the oxidant was dropped in, the reaction mixture was left with constant stirring at $0{ }^{\circ} \mathrm{C}$ for additional three hours. Subsequently, the mixture was left to warm up to room temperature. Polyaniline was collected on a Schott funnel, washed with $1 \mathrm{M} \mathrm{HCl}$ and distilled water, until the washing liquid became colourless. The obtained polyaniline hydrochloride was converted to the base form by stirring with $0.1 \mathrm{M} \mathrm{NH}_{3}$ aqueous solution for 48 hours; this was followed by washing with water and methanol. Finally, the polymer was dried at room temperature in air and then dried under dynamic vacuum for 48 hours.

A coating of emeraldine base on steel substrate pretreated with 8hydroxyquinoline sulphonic acid (HQSA) was obtained by solution evaporation 
method. The solubility of EB was checked in different solvents like dimethyl sulfoxide (DMSO), acetone and TMU and finally settled for TMU. A saturated solution of EB in TMU was prepared, filtered and placed on the surface of steel with help of a dropper. The pouring of the solution on steel surface was continued till a thick and uniform coating was obtained. The weight of the coating per unit area was measured and found to be $6.54 \mathrm{mg} / \mathrm{cm}^{2}$. More coated samples were obtained following identical procedure and care was taken that weight of the coating is maintained to $6.54 \mathrm{mg} / \mathrm{cm}^{2}$ with a variation of $\pm 5 \%$.

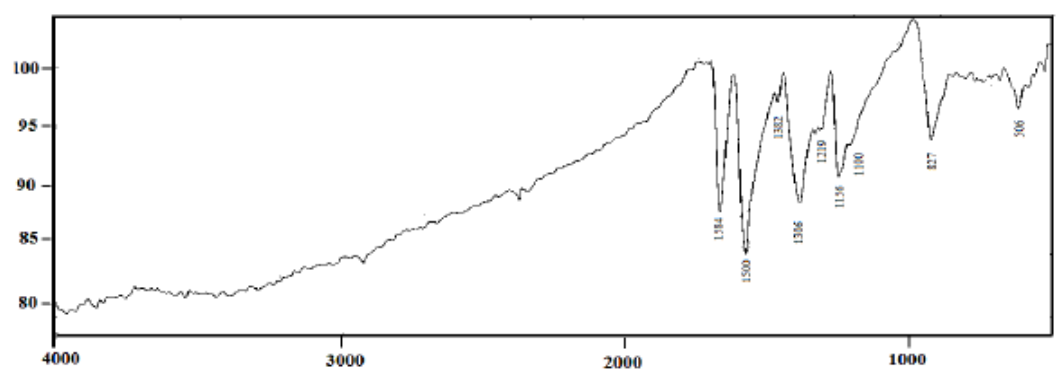

(a)

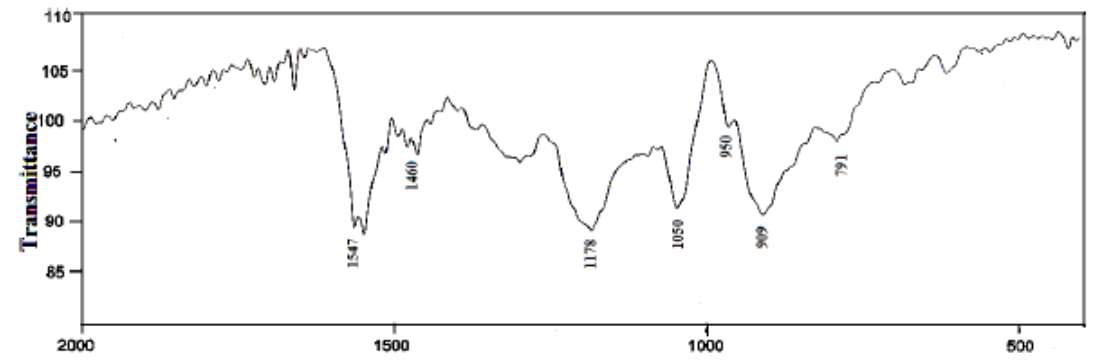

(b)

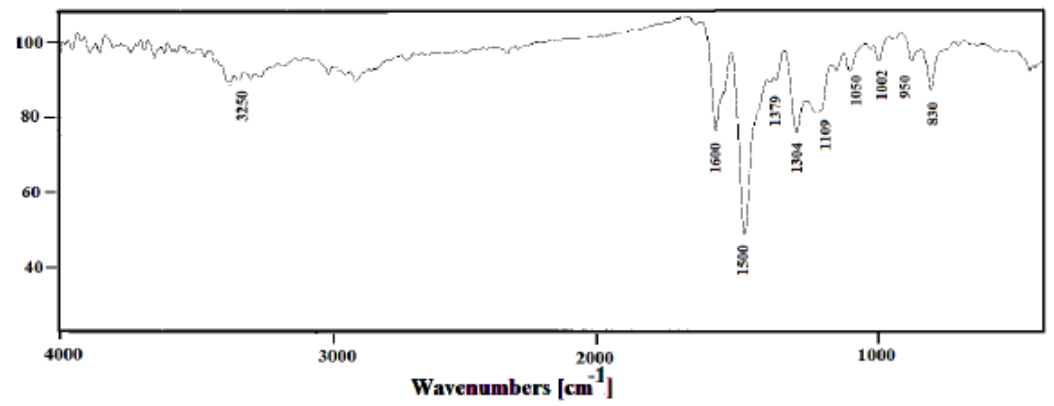

(c)

Figure 1. FTIR absorption spectra of (a) EB, (b) PPy and (c) PPy/EB coatings.

\section{Synthesis and preparation of polypyrrole coating}

The synthesis of polypyrrole coating on mild steel was carried out by chemical polymerization. A solution of pyrrole in $\mathrm{HCl}$ was prepared by dissolving $2.7 \mathrm{~mL}$ of pyrrole in $100 \mathrm{~mL}$ of $0.1 \mathrm{M} \mathrm{HCl}$. Pre-weighed steel specimen was dipped in this solution for 10 minutes. A solution of $\left[\left(\mathrm{NH}_{4}\right)_{2} \mathrm{~S}_{2} \mathrm{O}_{8}\right]$ in $\mathrm{HCl}$ was prepared by dissolving $3.0 \mathrm{gm}$ of $\left[\left(\mathrm{NH}_{4}\right)_{2} \mathrm{~S}_{2} \mathrm{O}_{8}\right]$ in $100 \mathrm{~mL}$ of $0.1 \mathrm{M} \mathrm{HCl}$ and added drop wise in the pyrrole solution containing specimen with continuous stirring till the solution turned green. The specimen was left in the solution till a thin black 
coating was obtained. The specimen was taken out and dried at room temperature.

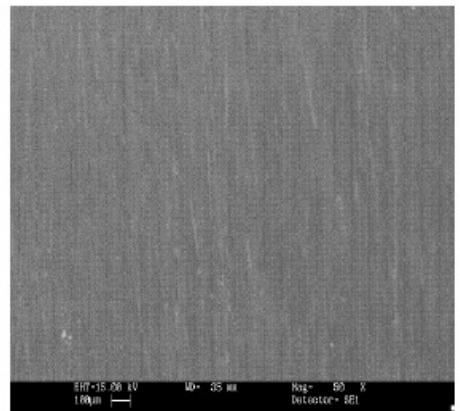

(a)

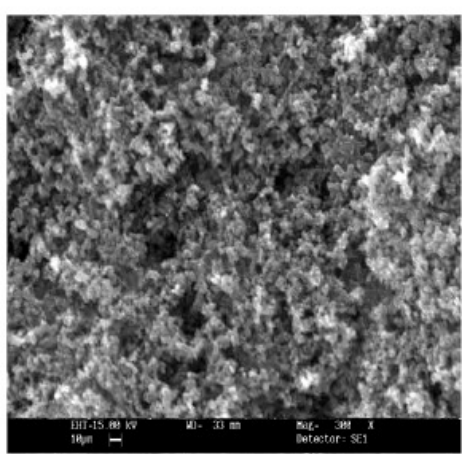

(c)

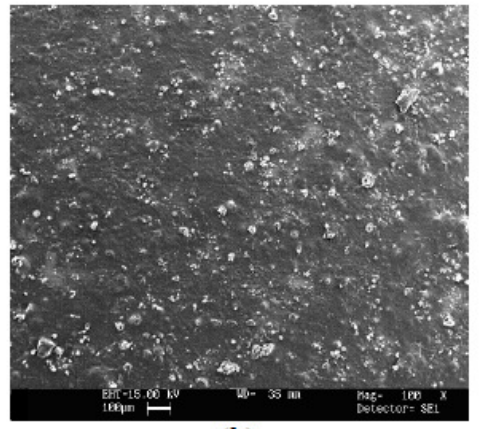

(b)

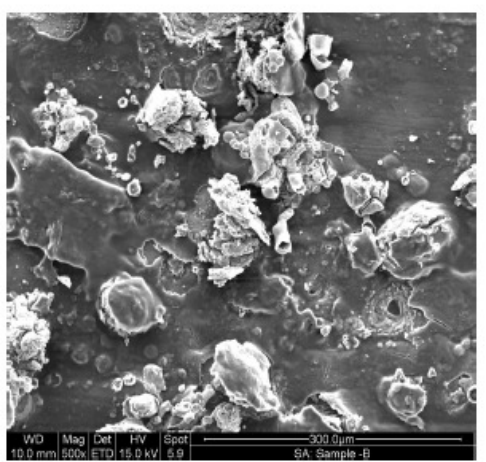

(d)

Figure 2: SEM micrographs of (a) uncoated steel, (b) EB, (c) PPy and (d) PPy/EB coated steel specimens.

\section{Preparation of $P P y / E B$ coating}

A top coat of EB was obtained on the PPy coated steel surface by following the identical procedures mentioned above. The thickness and uniformity of top coat of EB was adjusted by controlled addition of EB solution.

\section{Characterization of single and bi-layered coatings}

The FTIR transmission spectrum of EB, PPy and PPy/EB coatings were recorded in horizontally attenuated total reflectance (HATR) mode using FTIR [Model: Thermo Nicolet, Lexus] and the results are produced in Fig. 1.

\section{Morphological analysis of polymer coatings}

The surface morphology of polymer coatings was evaluated using scanning electron microscopy (SEM) (Model: FEI, Quanta 200). The SEM micrographs of uncoated, EB, PPy and PPy/EB coated specimen are shown in Fig. 2 (a - d). The SEM micrograph of EB coated specimen shows grainy type morphology (Fig. 2 b), whereas the PPy coated specimen shows a globular type spheroidal morphology (Fig. 2 c). In case of PPy/EB coated specimen EB particles are uniformly dispersed over PPy coating (Fig. 2 d). The SEM micrograph of $\mathrm{PPy} / \mathrm{EB}$ coated specimen corroded in $0.1 \mathrm{M} \mathrm{HCl}$ and $5 \% \mathrm{NaCl}$ solution is shown in Fig. 3 ( $a$ and b), respectively. Formation of fine crack is visible on the surface. In case PPy/EB coated specimen corroded in $\mathrm{NaCl}$ solution onset of tunnel after 30 days of exposure is also evident in the micrograph. 


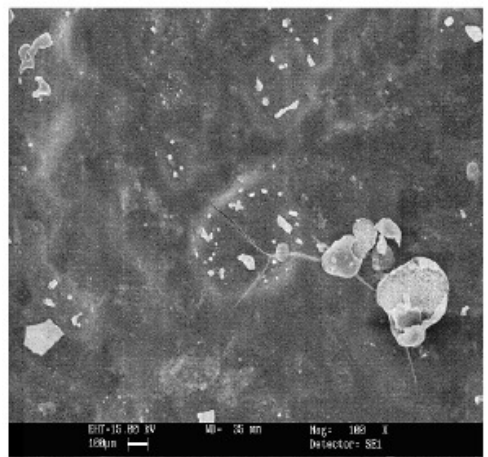

(a)

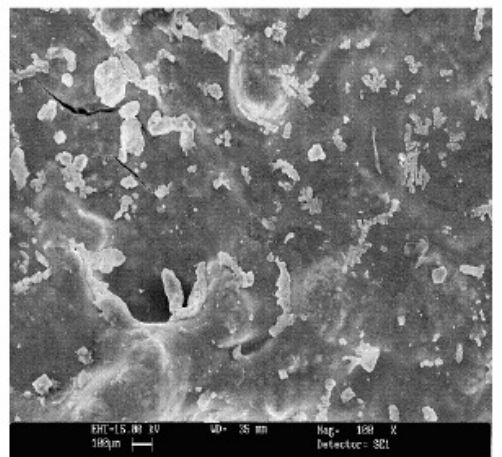

(b)

Figure 3: SEM micrographs of (a) PPy/EB coated after immersion in $0.1 \mathrm{M} \mathrm{HCl}$ and (b) $\mathrm{PPy} / \mathrm{EB}$ coated after immersion in $5 \% \mathrm{NaCl}$ solution.

\section{Corrosion performance of the polymer coatings}

In order to evaluate the corrosion protection performance of the polymer coating in different corrosive environments uncoated, EB, PPy and PPy/EB coated mild steel specimens were subjected to immersion test, free corrosion potential measurements and potentiodynamic polarization measurements. The corrosive environments include: $0.1 \mathrm{M} \mathrm{HCl}, 5 \% \mathrm{NaCl}$ solution, artificial seawater, distilled water, tap water and open atmosphere. All the electrochemical measurements were done at room temperature under static condition.

\section{Immersion test}

After taking the initial weight and dimension, uncoated and polymer coated specimens were hanged in test solution with the help of nylon thread. The tests were carried out under static condition at room temperature for a period extending 30 days. The corrosion rate was calculated from determination of total iron ions $\left(\mathrm{Fe}^{2+}, \mathrm{Fe}^{3+}\right)$ entered into the test solution in the course of corrosion during immersion. The analysis was performed spectrophotometrically [23, 24] using a double beam spectrophotometer [Model: Elico-SL-169 UV- Visible Spectrophotometer]. The corrosion rate was calculated using the following relationship:

$$
\text { Corrosion rate }=\frac{m}{s \times t}\left[\mathrm{gm}^{-2} \mathrm{~h}^{-1}\right]
$$

where, ' $m$ ' is the mass of corroded metal (calculated from the total iron content determined in the test solution), ' $s$ ' is the area of the test metal in $\mathrm{m}^{2}$, and ' $t$ ' is the exposure time in hrs. The protection efficiency (\%PE) of the coated specimen was evaluated using the following equation:

$$
(\% P E)=\frac{C R u-C R c}{C R u} \times 100
$$


where, $C R u$ is the corrosion rate of mild steel in absence of coating, and $C R c$ is corrosion rate of mild steel in presence of coating.

\section{Free corrosion potential measurement}

The free corrosion potential measurements of uncoated and coated steel specimens were measured in $0.1 \mathrm{M} \mathrm{HCl}, 5 \% \mathrm{NaCl}$, artificial seawater, distilled water and tap water. The change in voltage against saturated calomel electrode (SCE) used as reference electrode was plotted vs. time. The steel specimen was connected to a wire having alligator clips on both the ends. One end of the alligator clip was attached to the steel specimen and placed into the corrosive solution and the other end was connected to a multi meter. The potential measurement in a particular medium was continued till a steady state was obtained or it went down to the potential of bare steel.

\section{Potentiodynamic polarization measurements}

The potentiodynamic polarization measurements were carried out on an EG\&G potentiostat / galvanostat model $263 \mathrm{~A}$. The experiments were carried out using a corrosion cell from EG\&G model $\mathrm{K} 0047$ with $\mathrm{Ag} / \mathrm{AgCl}$ electrodes (saturated $\mathrm{KCl})$ as reference and $\mathrm{Pt}$ wire as counter electrode. The potentiodynamic polarization measurements were performed using a scan rate of $0.166 \mathrm{mV} / \mathrm{s}$ commencing at a potential above $250 \mathrm{mV}$ more active than the stable open circuit potential. Before starting the measurements the specimen was left to attain a steady state which was indicated by a constant potential.

\section{Atmospheric exposure test}

The EB and PPy/EB coated steel samples along with uncoated steel sample were weighed and subsequently fixed on a panel which stood on a heavy metallic base and placed at the roof of the department. The exposure time was 30 days. The samples were taken off from the panel after the completion of the exposure test and physically examined for coating deterioration. To further examine the effect of atmosphere on the corrosion performance of the polymer coatings, the samples obtained after exposure to open atmosphere were immediately immersed in distilled water and were subjected to potentiodynamic polarization measurements.

\section{Results and discussion}

\section{FTIR spectra of the EB, PPy and PPy/EB coatings}

The FTIR spectrum of EB, PPy and PPy/EB is shown in Fig. 1. The spectrum of the EB [25] and PPy [26, 27] is consistent with the reported spectrum of polymers. Considering the FTIR spectrum of EB (Fig.1a), the peak observed at $1584 \mathrm{~cm}^{-1}$ corresponds to $\mathrm{C}=\mathrm{C}$ stretching of quinoid ring, whereas vibration band at $1500 \mathrm{~cm}^{-1}$ arises due to vibration of $\mathrm{C}=\mathrm{C}$ double bond associated with the benzenoid ring. The peak at $1378 \mathrm{~cm}^{-1}$ is assigned to $\mathrm{C}-\mathrm{C}$ stretch in a quinoid ring, whereas peak at $1306 \mathrm{~cm}^{-1}$ is due to $\mathrm{C}-\mathrm{H}$ bending. The band at $1219 \mathrm{~cm}^{-1}$ is 
due to $\mathrm{C}-\mathrm{N}$ stretching and $\mathrm{C}-\mathrm{H}$ bending. Peaks at $827 \mathrm{~cm}^{-1}$ and $506 \mathrm{~cm}^{-1}$ are due to deformational $\mathrm{C}-\mathrm{H}$ (out of plane) of 1-4 disubstituted aromatic rings.

The FTIR spectrum of polypyrrole is shown in Fig. 2 b. The peak at $1547 \mathrm{~cm}^{-1}$ corresponds to $\mathrm{C}=\mathrm{C}$ stretching vibration. The peak observed at $1460 \mathrm{~cm}^{-1}$ is attributed to $\mathrm{C}-\mathrm{N}$ stretching vibration in the polymer and at $1178 \mathrm{~cm}^{-1}$ for $\mathrm{C}=\mathrm{C}$ bond stretching. The peaks around 909 and $791 \mathrm{~cm}^{-1}$ are due to deformation of PPy unit. Fig. $2 \mathrm{c}$ shows the FTIR spectrum of PPy/EB. The characteristic peaks for PPy are shown at 1050 and $950 \mathrm{~cm}^{-1}$, whereas the EB characteristic IR peaks are shown at 3250, 1600, 1500 and $830 \mathrm{~cm}^{-1}$.

Table 1. Results of immersion test.

\begin{tabular}{|l|l|c|c|c|}
\hline $\begin{array}{c}\text { Corrosive } \\
\text { medium }\end{array}$ & $\begin{array}{c}\text { Description of the } \\
\text { sample }\end{array}$ & $\begin{array}{c}\text { Immersion period } \\
\text { (days) }\end{array}$ & $\begin{array}{c}\text { Corrosion rate } \\
(\mathbf{m p y})\end{array}$ & \% PE \\
\hline $0.1 \mathrm{M} \mathrm{HCl}$ & Uncoated steel & 30 & 19.081 & - \\
\hline & EB coated &, & 5.01 & 73.69 \\
\hline & PPy coated &,, & 8.03 & 57.91 \\
\hline & PPy/EB coated &, & 4.50 & 76.41 \\
\hline $5 \% \mathrm{NaCl}$ solution & Uncoated steel &, & 6.02 & - \\
\hline & EB coated &, & 2.51 & 58.30 \\
\hline & PPy coated &, & 3.41 & 43.35 \\
\hline & PPy/EB coated &, & 1.50 & 75.08 \\
\hline Artificial seawater & Uncoated steel &, & 7.03 & - \\
\hline & EB coated &, & 2.61 & 62.87 \\
\hline & PPy coated &, & 4.01 & 42.57 \\
\hline & PPy/EB coated &, & 1.50 & 78.66 \\
\hline Distilled water & Uncoated &, & 4.03 & - \\
\hline & EB coated &, & 2.01 & 50.12 \\
\hline & PPy coated &, & 2.51 & 37.40 \\
\hline & PPy/EB coated &, & 1.01 & 72.50 \\
\hline Tap water & Uncoated steel &, & 5.02 & - \\
\hline & EB coated &, & 3.58 & 48.06 \\
\hline & PPy coated &, & & 40.04 \\
\hline & PPy/EB coated &, 1.41 & 71.91 \\
\hline
\end{tabular}

\section{Immersion test}

Table 1 shows the results of immersion tests for uncoated, EB, PPy and PPy/EB coated mild steel specimens immersed in different corrosive solutions. The test was carried out under static condition at room temperature for the duration of 30 days. Out of the five different corrosive solutions selected for the corrosion studies, tap water and distilled water are least corrosive, whereas $0.1 \mathrm{M} \mathrm{HCl}$ solution is most corrosive. The severity of $5 \% \mathrm{NaCl}$ solution and that of artificial seawater are comparable. Comparing the corrosion performance of monolayer (EB and PPy) with bilayer coatings, the PPy/EB coating performed much better than monolayer coatings as it effectively hindered the attack of corrosive environments. The better performance of PPy/EB coating is attributed to an increased thickness and reduction in the porosity of the coating. The increased thickness and reduced porosity of PPy/EB coating lengthen the diffusion path of the corrodent thereby increasing the protection efficiency (PE ranged between $72-79 \%)$. The performance of single EB coating was found satisfactory only in 
$0.1 \mathrm{M} \mathrm{HCl}$, where it showed a protection efficiency of $73.69 \%$. However it showed better performance than PPy coating in all corrosive medium. The improved performance of EB over PPy is again attributed to higher thickness of EB coating.

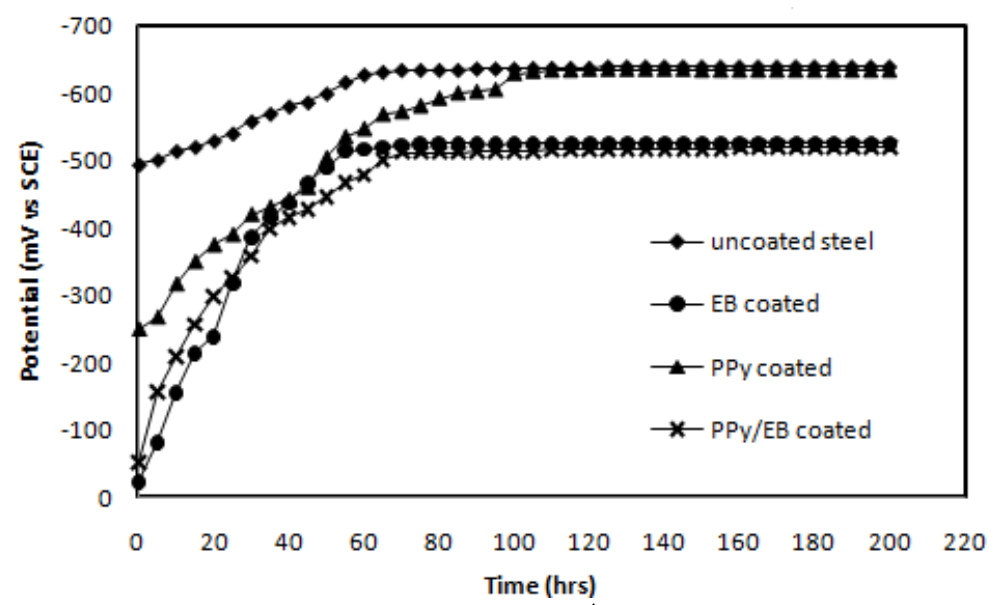

Figure 4. $E_{\text {corr }}$ vs. time plot in $0.1 \mathrm{M} \mathrm{HCl}$ for $(\bullet)$ uncoated steel; $(\bullet)$ EB coated; $(\boldsymbol{\Delta})$ PPy coated and $(x)$ PPy/EB coated.

\section{Open circuit potential (OCP) measurements}

The OCP values $\left(E_{\text {ocp }}\right)$ of uncoated, EB, PPy and PPy/EB coated steel were monitored with time in five different solutions and the results are shown in Fig. 4-8. Fig. 4 shows the $E_{\text {corr }}$ vs. time plot for uncoated, EB, PPy and PPy/EB coated steel in $0.1 \mathrm{M} \mathrm{HCl}$. The initial potential of uncoated steel is $-495 \mathrm{mV}$; this is followed by an increase in negative potential with increasing exposure period till a near steady state is attained at a value of $-635 \mathrm{mV}$. This value remained constant up to the end of $200 \mathrm{hrs}$ of immersion. The initial potential of EB, PPy and PPy/EB coated steel is measured to be $-23 \mathrm{mV},-250 \mathrm{mV}$ and $-52 \mathrm{mV}$, respectively. These values are quite anodic than the corrosion potential of uncoated steel measured for the same condition. The initial potential of PPy coated steel is comparatively higher than the initial potential of $\mathrm{EB}$ and PPy/EB coatings, but it is still nobler than the potential of uncoated steel. With increasing immersion period, there is a continuous increase in the negative potential till a steady potential is obtained. However, the final potential is still nobler than the potential of uncoated steel. In general, the performance of mono and bilayer coatings in other solutions (Fig. 5-8) is similar to that in $0.1 \mathrm{M} \mathrm{HCl}$.

The positive shift in the corrosion potential for EB, PPy and PPy/EB coated steel in all the corrosive solutions under investigation is indicative of their strong passivating property of polymer coatings and formation of a passive oxide layer. The presence of a dense and adherent coating on the steel substrate provided an effective barrier behavior to both single and bilayer polymer coatings against the attack of corrosive environment. The initial OCP started to increase as a result of the initiation of corrosion process under the coating due to water up taking process by the coatings leading to anodic dissolution of steel. With increased exposure period, more and more electrolyte is held under the coating, increasing 
the mobility of the corrosive species in the coating and, as a result, further increasing the anodic dissolution of metal and diminishing the barrier efficiency of the coatings. The initiation and progression of corrosion phenomenon under the coating depended upon the thickness and porosity of the coating. As a result of higher thickness and reduced porosity the performance of PPy/EB was found better or comparable with EB coating and superior than PPy coating.

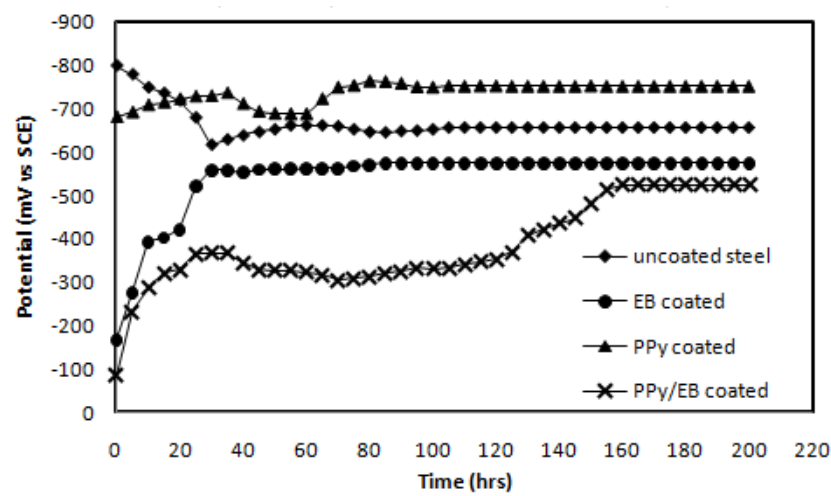

Figure 5. $E_{\text {corr }}$ vs. time plot in $5 \% \mathrm{NaCl}$ for $(\diamond)$ uncoated steel; $(\bullet)$ EB coated; ( $\left.\boldsymbol{\Delta}\right)$ PPy coated and $(x)$ PPy/EB coated.

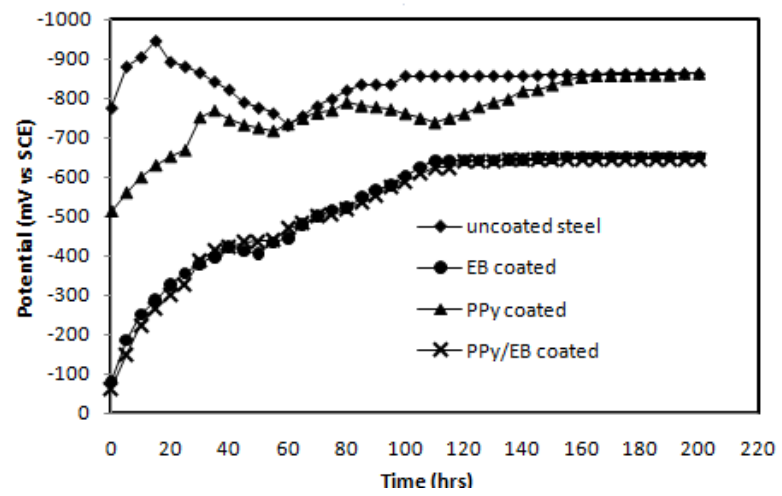

Figure 6. $E_{\text {corr }}$ vs. time plot in artificial seawater for $(\diamond)$ uncoated steel; $(\bullet)$ EB coated; $(\boldsymbol{\Delta})$ PPy coated and $(x)$ PPy/EB coated.

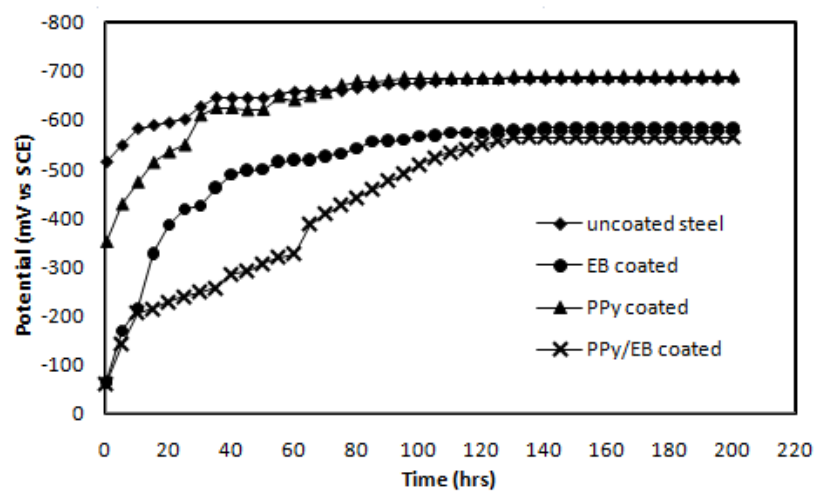

Figure 7. $E_{\text {corr }}$ Vs. time plot in distilled water for $(\diamond)$ uncoated steel; $(\bullet)$ EB coated; $(\boldsymbol{\Delta})$ PPy coated and (x) PPy/EB coated. 


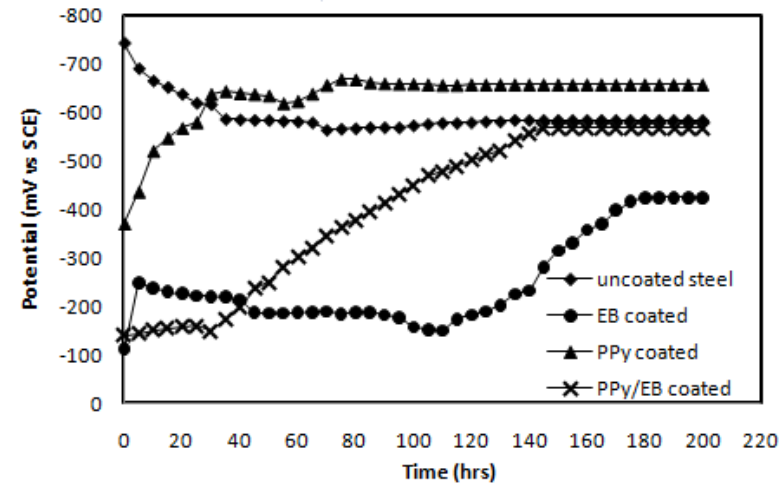

Figure 8. $E_{\text {corr }}$ Vs. time plot in tap water for $(\diamond)$ uncoated steel; $(\bullet)$ EB coated; $(\boldsymbol{\Delta})$ PPy coated and $(x)$ PPy/EB coated.

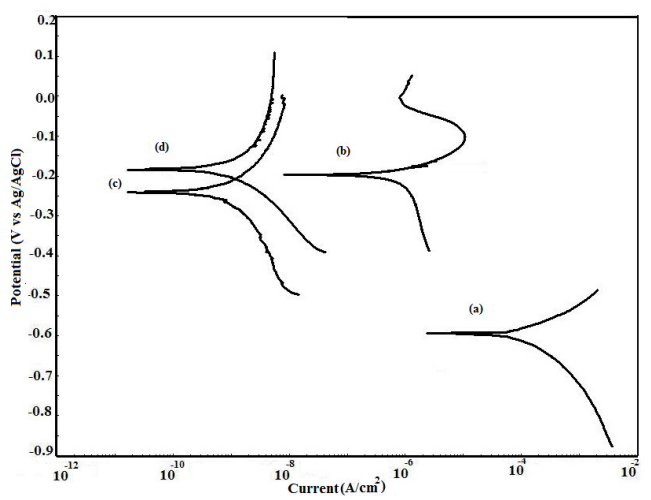

Figure 9. Potentiodynamic polarization curves in $0.1 \mathrm{M} \mathrm{HCl}$ for (a) uncoated steel; (b) EB coated; (c) PPy coated and (d) PPy/EB coated.

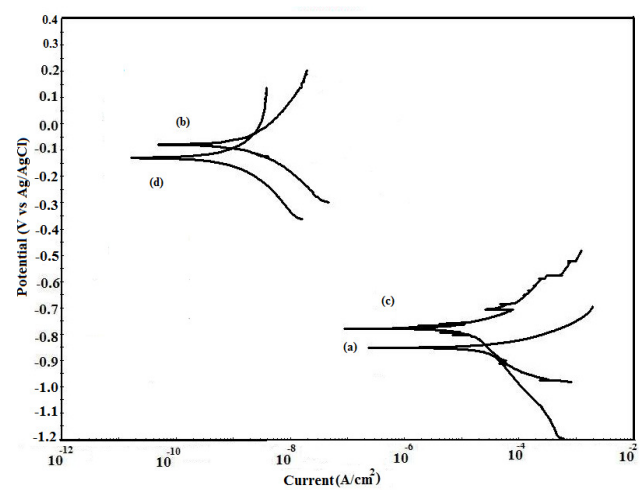

Figure 10. Potentiodynamic polarization curves in $5 \% \mathrm{NaCl}$ for (a) uncoated steel; (b) EB coated; (c) PPy coated and (d) PPy/EB coated.

\section{Potentiodynamic polarization measurements}

The potentiodynamic polarization curves for uncoated, EB, PPy and PPy/EB coated steel recorded in $0.1 \mathrm{M} \mathrm{HCl}, 5 \% \mathrm{NaCl}$ solution, artificial sea water, distilled water and tap water, respectively, are shown in Fig. 9-13. The values of corrosion potential $\left(E_{\text {corr }}\right)$, corrosion current density $\left(I_{\text {corr }}\right)$, and corrosion rate obtained from these curves are listed in Table 2. The Tafel extrapolations show that both mono and bi-layer coated steel caused a significant positive shift in the corrosion potential $\left(E_{\text {corr }}\right)$, relative to the $E_{\text {corr }}$ value of the uncoated steel. This positive shift in the $E_{\text {corr }}$ confirms the strong passivating property of polymer 
coatings. Tafel measurements show a significant reduction in corrosion current density $\left(I_{\text {corr }}\right)$ for EB, PPy and PPy/EB coated steel with respect to uncoated steel in all corrosive media under study. The corrosion rate of polymer coated steel is substantially lowered as a result of the reduction in $I_{\text {corr }}$ values. In general, the corrosion rate of $\mathrm{PPy} / \mathrm{EB}$ coating is lower than mono layer coatings in all the corrosive solutions and is consistent with the results of immersion test. The better performance of PPy coating during potentiodynamic polarization studies is attributed to instantaneous measurements of corrosion parameters; the coating is less affected by corrosive solutions and its barrier property is only slightly diminished. However, due to lower thickness the coating was more affected during long exposure to corrosive solutions thereby showing poor performance in the immersion tests.

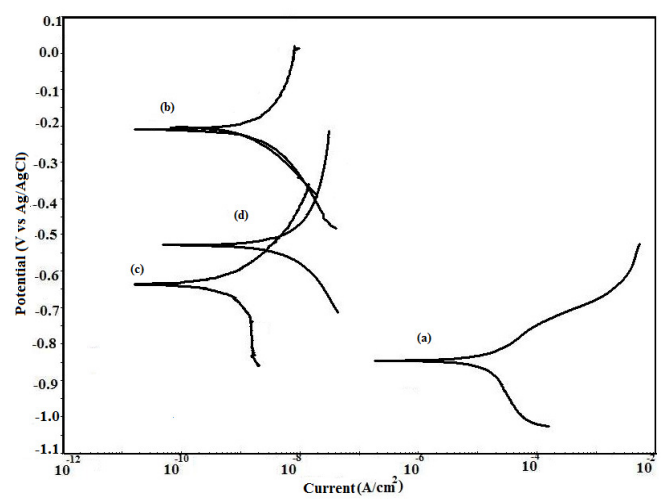

Figure 11. Potentiodynamic polarization curves in artificial seawater for (a) uncoated steel; (b) EB coated; (c) PPy coated and (d) PPy/EB coated.

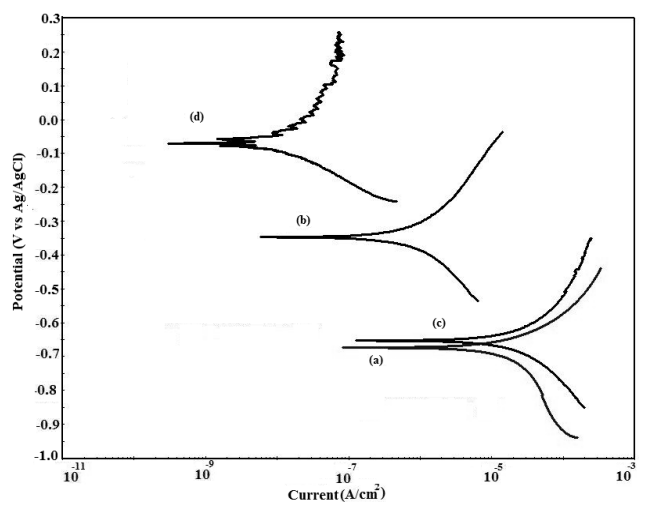

Figure 12. Potentiodynamic polarization curves in distilled water for (a) uncoated steel; (b) EB coated; (c) PPy coated and (d) PPy/EB coated. 


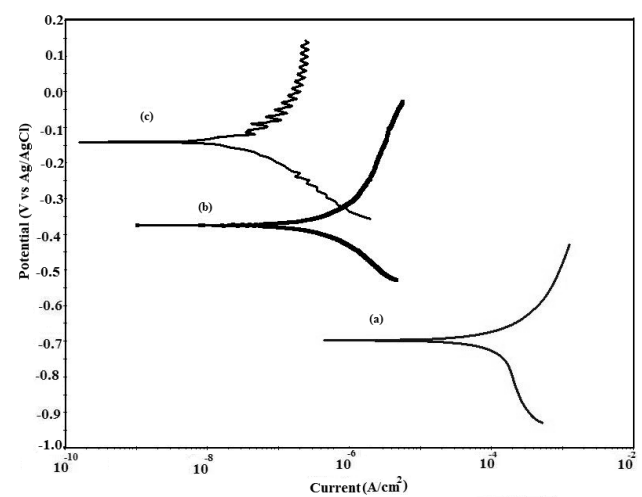

Figure 13. Potentiodynamic polarization curves in $5 \% \mathrm{NaCl}$ for (a) uncoated steel; (b) EB coated; (c) PPy coated and (d) PPy/EB coated.

Table 2. Results of potentiodynamic polarization measurements.

\begin{tabular}{|c|c|c|c|c|}
\hline \multirow{2}{*}{$\begin{array}{l}\text { Corrosive } \\
\text { medium }\end{array}$} & \multirow{2}{*}{ Coating system } & \multicolumn{3}{|c|}{$\begin{array}{l}\text { Polarization parameters } \\
\end{array}$} \\
\hline & & $I_{c o r r} /\left(\mu \mathrm{A} / \mathrm{cm}^{2}\right)$ & $E_{\text {corr }} /(\mathbf{m V})$ & Corrosion rate/(mpy) \\
\hline \multirow{4}{*}{$0.1 \mathrm{M} \mathrm{HCl}$} & Uncoated steel & 1994.001 & -522 & 33.01 \\
\hline & EB coated & 10.061 & -195 & 0.171 \\
\hline & PPy coated & 0.030 & -247 & 0.006 \\
\hline & PPy/EB coated & 0.022 & -189 & 0.004 \\
\hline \multirow{4}{*}{$\begin{array}{l}5 \% \mathrm{NaCl} \\
\text { solution }\end{array}$} & Uncoated steel & 265.512 & -851 & 4.543 \\
\hline & EB coated & 0.024 & -76 & 0.005 \\
\hline & PPy coated & 105.913 & -779 & 1.816 \\
\hline & PPy/EB coated & 0.033 & -132 & 0.006 \\
\hline \multirow{4}{*}{$\begin{array}{l}\text { Artificial } \\
\text { seawater }\end{array}$} & Uncoated steel & 144.713 & -846 & 2.536 \\
\hline & EB coated & 0.064 & -210 & 0.001 \\
\hline & PPy coated & 0.023 & -638 & 0.004 \\
\hline & PPy/EB coated & 0.022 & -529 & 0.003 \\
\hline \multirow{4}{*}{$\begin{array}{l}\text { Distilled } \\
\text { water }\end{array}$} & Uncoated steel & 54.511 & -673 & 0.922 \\
\hline & EB coated & 1.629 & -347 & 0.027 \\
\hline & PPy coated & 87.531 & -652 & 1.501 \\
\hline & PPy/EB coated & 0.024 & -75 & 0.005 \\
\hline \multirow{4}{*}{ Tap water } & Uncoated & 483.210 & -697 & 8.078 \\
\hline & EB coated & 1.685 & -375 & 0.028 \\
\hline & PPy coated & 0.004 & -515 & 0.007 \\
\hline & PPy/EB coated & 0.003 & -99 & 0.004 \\
\hline
\end{tabular}

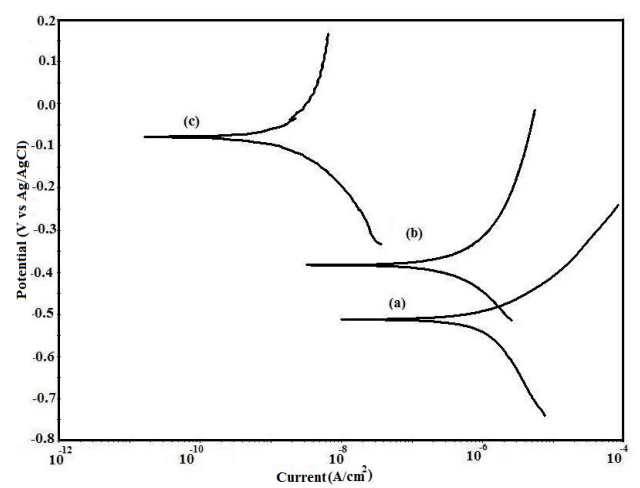

Figure 14. Potentiodynamic polarization curves in distilled water for (a) uncoated steel; (b) EB coated and (c) PPy/EB coated steel after 30 days exposure to open atmosphere. 


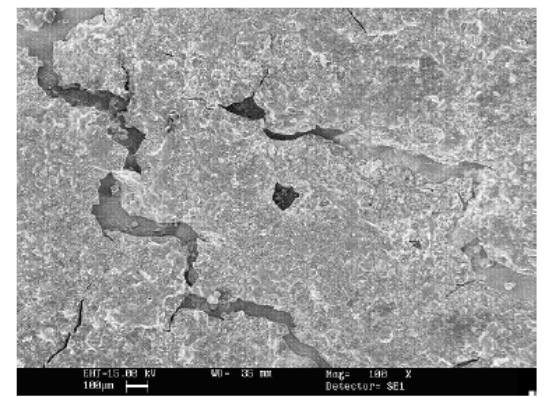

Figure 15. SEM micrograph of PPy/EB coated steel specimen after 30 days exposure to open atmosphere.

\section{Atmospheric test}

The samples taken after the completion of the atmospheric test were physically examined and photographed. The coating was found to be detached from the substrate at some places (Fig. 15). The potentiodynamic polarization curves for uncoated, EB and PPy/EB coated steel samples recorded in distilled water after 30 days exposure to open atmosphere are shown in Fig. 14. The values of corrosion potential $\left(E_{\text {corr }}\right)$, corrosion current density $\left(I_{\text {corr }}\right)$ and corrosion rates as computed from the above curves are shown in Table 3. The Tafel extrapolations show a positive shift in corrosion potential and lowering in corrosion current density for the coated steel with respect to bare steel for the same condition. It is clearly seen that after one month of atmospheric exposure, though the adherence of the polymer coatings is affected but the corrosion rate is still lower than the uncoated steel. This confirms the self passivating nature of coatings and suggests the operation of an additional protection mechanism in addition to barrier effect.

Table 3. Results of potentiodynamic polarization measurements after 1 month exposure to open atmosphere.

\begin{tabular}{|c|c|c|c|}
\hline Coating system & $\boldsymbol{I}_{\text {corr }} /\left(\boldsymbol{\mu} \mathbf{A} / \mathbf{c m}^{2}\right)$ & $\boldsymbol{E}_{\text {corr }} /(\mathbf{m V})$ & Corrosion rate/(mpy) \\
\hline Uncoated steel & 15.271 & -511 & 1.152 \\
\hline EB coated & 13.511 & -324 & 1.019 \\
\hline PPy/EB coated & 0.123 & -106 & 0.009 \\
\hline
\end{tabular}

\section{Conclusions}

Good adherent and uniform coatings of EB, PPy and PPy/EB on mild steel were successfully obtained by chemical deposition. The results of immersion tests show higher protection efficiency for PPy/EB coated steel (PE: 72-79\%) than EB (PE: 48-74\%) and PPy (PE: 37-58\%) coated steel in all corrosive medium under investigation. The results of $E_{\text {corr }}$ vs. time plots show a significant positive shift in the corrosion potential for both single and bi-layered coated steel, indicating the strong passivating and effective barrier behavior of the above coating system against the attack of corrosive environments. The electrochemical parameters as derived from potentiodynamic polarization studies indicate much lower corrosion rates for the coated steel than uncoated steel. The obtained results show that the performance of $\mathrm{PPy} / \mathrm{EB}$ coating is better than EB and PPy coatings whereas the performance of PPy coating is inferior to both EB and PPy/EB coatings. 


\section{Acknowledgement}

The authors thankfully acknowledge the University Grants Commission, New Delhi, for financial assistance.

\section{References}

1. A.J. Heeger, Rev. Mod. Phys. 73 (2001) 681. 10.1103/RevModPhys.73.681

2. A.G. MacDiarrmid, Rev. Mod. Phys. 73(3) (2001) 701. 10.1103/RevModPhys.73.701

3. H. Shirakawa, Rev. Mod. Phys. 73(3) (2001) 713. 10.1103/RevModPhys.73.713

4. G. Mengoli, M.T. Munari, P. Bianco, M.M. Musiani, J. Appl. Polym. Sci. 26 (1981) 4247. 10.1002/app.1981.070261224

5. $\quad$ N. Ahmad, A.U. Malik, M. Mobin, J. Ind. Chem. Soc. 84 (2007) 1.

6. P. Pawar, A.B. Gaikwad, P.P. Patil, Sci. Tech. Adv. Mat. 7 (2006) 732. 10.1016/j.stam.2006.09.014

7. Y. Chem, X.H. Wang, J. Li, J.L. Lu, F.S. Wang, Corrosion Sci. 49 (2007) 3052. 10.1016/j.corsci.2006.11.007

8. J. Fang, K. Xu, L. Zhu, Z. Zhou, H. Tang, Corrosion Sci. 49 (2007) 4232. 10.1016/j.corsci.2007.05.017

9. A.T. Ozyilmaz, M. Ebril, B. Yazici, Thin Solid Films 496 (2006) 431. 10.1016/j.tsf.2005.08.306

10. S. Sathiyanarayanan, S. Devi, G. Venkatachari, Prog. Org. Coat. 56 (2006) 114. 10.1016/j.porgcoat.2006.01.003

11. J. Reut, A. Opik, K. Idla, Synth. Met. 102 (1999) 1392. 10.1016/S03796779(98)01036-4

12. N.V. Krstajic, B.N. Grgur, S.M. Jovanovic, M.V. Vojnovic, Electrochim. Acta 42 (1997) 1685.

13. M.G. Hosseini, M. Sabouri, T. Shahrabi, Prog. Org. Coat. 60 (2007) 178. 10.1016/j.porgcoat.2007.07.029

14. C.A. Ferreira, S. Aeiyach, J.J. Aaron, P.C. Lacaze, Electrochim. Acta 41 (1996) 1801. 10.1016/0013-4686(95)00498-X

15. J. Petitjean, S. Aeiyach, J.C. Lacroix, P.C. Lacaze, J. Electroanal. Chem. 478 (1999) 92. 10.1016/S0022-0728(99)00418-0

16. N. Ahmad, A.G. MacDiarrmid, Synth. Met. 78 (1996) 103. 10.1016/03796779(96)80109-3

17. J.R. Santos, L.H. Mattoso, A.J. Motheo, Electrochim. Acta 43 (1998) 309. 10.1016/S0013-4686(97)00052-2

18. T.P. McAndrew, S.A. Miller, A.G. Gilicinski, L.M. Robeson, Polym. Mat. Sci. Eng. 74 (1996) 204.

19. Y. Wei, J. Wang, X. Jia, J.M. Yeh, P. Spellama, Polymer 36 (1995) 4535. 10.1016/0032-3861(95)96866-7

20. A. Talo, O. Forsen, S. Ylasaari, Synth. Met. 102 (1999) 1394. 10.1016/s03796779(98)01050-9

21. W.S. Araujo, I.C.P. Margarit, M. Ferreira, O.R. Mattos, P.L. Neto, Electrochim. Acta 46 (2001) 1307. 10.1016/S0013-4686(00)00726-X 
22. C.K. Tan, D.J. Blackwood, Corrosion Sci. 45 (2003) 545. 10.1016/S0010938X(02)00144-0

23. R. Vera, R. Schrebler, P. Cury, R.R. Del, H. Romero, J. Appl. Electrochem. 37 (2007) 519. 10.1007/s10800-011-0272-5

24. R. Ansari, AH. Alikhani, J. Coat. Technol. Res. 6 (2009) 221. 10.1007/s11998-008-9140-6

25. E.T. Knag, K.G. Neoh, K.L. Tan, Prog. Polym. Sci. 23 (1998) 277. 10.1016/S0079-6700(97)00030-0

26. M.S. Bosnar, M.V. Budimir, S. Kovoc, D. Kukulj, L. Duic, Polym. Sci. Part A Polym. Chem. 30 (1992) 1609. 10.1002/pola.1992.080300813

27. E.T. Knag, K.G. Neoh, T.C. Tan, Y.K. Ong, J. Macromol. Sci. Chem. A 24 (1987) 631. 10.1080/00222338708058518 